\title{
Observations on phagocytosis of urate crystals by polymorphonuclear leucocytes
}

\author{
K. T. RAJAN \\ From the Oxford Regional Rheumatic Diseases Research Centre, Stoke Mandeville Hospital, \\ Aylesbury, Bucks.
}

\begin{abstract}
Rajan, K. T. (1975). Annals of the Rheumatic Diseases, 34, 54. Observations on phagocytosis of urate crystals by polymorphonuclear leucocytes. The sequence of events that may initiate the inflammatory reaction in acute gout has been investigated with specific reference to phagocytosis of urate crystals by polymorphonuclear leucocytes and the results have shown (1) that neutrophil leucocytes avidly ingest microcrystals of sodium monourate, (2) that this causes the rapid degranulation and disintegration of the leucocytes, (3) that fresh leucocytes ingest the debris and crystals liberated by the dead cells, and in their turn degranulate and die, thus possibly establishing a vicious circle in the system.
\end{abstract}

It has been recognized since the time of Garrod (1859) that acute attacks of gout are usually precipitated by deposition of crystals of uric acid in the joints and the surrounding tissue. It has been possible to produce acute attacks experimentally by the injection of crystals of sodium urate (Faires and McCarty, 1961, 1962). Similar attacks have also been produced by injecting other crystals such as xanthine, one of the intermediate products in uric acid metabolism (Freudweiler, 1899). During these acute attacks there is local inflammation and usually a synovial effusion.

Polymorphonuclear leucocytosis occurs in many acute inflammatory conditions. Increases in the numbers of neutrophil leucocytes are found in synovial effusions in rheumatoid arthritis, septic arthritis, and gout. The severity of the inflammatory reaction is dependent on the number of neutrophils that are available at the time of invasion by the bacteria or toxic agent. In agranulocytosis the reaction to bacterial invaders by the host is functionally deficient and acute gouty effusions provoked by injecting crystals of uric acid into joints can be abolished by pretreating the host with drugs like vinblastine which reduce the total number of leucocytes available (McCarty, 1965). Thus this acute inflammatory reaction depends, at least in part, on the participation of host neutrophil leucocytes.

As already stated, during the acute inflammatory phase of gout, the synovial effusions invariably contain large numbers of polymorphonuclear leucocytes (PMN) many of which have phagocytosed crystals and are in various stages of degranulation and dissolution.

In the work reported here, the response of PMN (human and rabbit) to microcrystals of uric acid has been studied in detail. Observations by phase contrast microscopy have been supplemented by examination of thin sections by electron microscopy.

\section{Materials and methods}

(1) HUMAN PMNS

Fresh blood from the forearm vein was collected in sterile siliconized tubes, containing heparin (2 500 units/ $\mathrm{ml}$ ); the blood was diluted to $1 / 10$ of its volume with $6 \%$ dextran in saline which was layered gently on top of the blood, after which the two were mixed. The tubes were sealed, allowed to stand at room temperature for $30 \mathrm{~min}$, and the clear plasma layer was removed with a wide bore pipette; most of the white cells were in this upper plasma layer. A sample was taken and a total cell count was made in Türk's solution. To facilitate counting and accurate identification of cells, acridine orange was added in a concentration of 1 in 100000 ; the granules of the PMN cells were easily identified by examination using fluorescence microscopy with a blue filter, when they appeared brilliant orange.

\section{(2) RABBIT PMNS}

Induced peritoneal exudates were used. Rabbits were primed with $0.1 \%$ glycogen in normal saline. On the day when the PMNs were to be harvested for studies on phagocytosis, $80-100 \mathrm{ml}$ of $0 \cdot 1 \%$ glycogen were injected intraperitoneally, and 3 to $4 \mathrm{~h}$ later $100 \mathrm{ml}$ of Hanks's balanced salt solutions were introduced with a no. 15 
needle. The peritoneal exudate was allowed to drip by gravity into sterile siliconized conical tubes or flasks containing heparin (1 $\mathrm{ml}$ heparin to $9 \mathrm{ml}$ exudate). Ordinarily 80 to $100 \mathrm{ml}$ of exudate were obtained. The red cells were lysed in hypotonic saline and the leucocytes were then washed with normal saline and centrifuged at 1000 r.p.m. for $10 \mathrm{~min}$. The cells from this pellet were resuspended in medium 199 with $4.4 \%$ sodium bicarbonate; the suspension contained $4 \times 10^{3}$ leucocytes $/ \mathrm{ml}$, of which over $98 \%$ were PMNs.

\section{(3) CULTURE TECHNiQUES}

As the period of observation was only just over $4 \mathrm{~h}$, the cells were cultured on single coverslips with medium 199 (Burroughs Wellcome). The cell suspension was deposited in the middle of a clean glass slide ( 3 in $\times 1$ in) and covered with a coverslip $(19 \mathrm{~mm} \times 38 \mathrm{~mm})$; three sides of the coverslip were sealed with sterile petroleum jelly. Crystals ranging in length from $0 \cdot 5-8 \mu \mathrm{m}$ were suspended in normal saline to make a saturated solution and a drop of the suspension was introduced into the preparation through the unsealed side of the coverslip. The slide, resting on a pad of wet cotton wool, was enclosed in a sterile petri dish and incubated at $37^{\circ} \mathrm{C}$ in a sealed incubator periodically flushed with $5 \%$ carbon dioxide in air.

To study phagocytosis, polymorphonuclear leucocytes in medium 199 were incubated for 5 to $15 \mathrm{~min}$ with a suspension of microcrystalline sodium monourate (Rajan, 1968) prepared from uric acid (BDH) by the technique of Seegmiller, Howell, and Malawista (1962).

Cultures were examined at half-minute intervals up to $2 \mathrm{~h}$. The process of phagocytosis was observed in the living cells vitally stained with 1:100000 acridine orange, both by phase contrast and fluorescence microscopy.

\section{(4) ELECTRON MICROSCOPY}

Pellets of leucocytes were fixed in $2.5 \%$ glutaraldehyde in $0.09 \mathrm{~mol} / \mathrm{l}$ cacodylate buffer, $\mathrm{pH} 7.2$, containing $3 \mathrm{~mol} / 1$ calcium chloride for $1 \mathrm{~h}$ at $4^{\circ} \mathrm{C}$. After washing with cacodylate buffer for $2 \mathrm{~h}$ (three changes) they were post-fixed in Zetterquist's buffered isotonic osmium tetroxide for $1 \mathrm{~h}$ (Glauert, 1965) and then washed in veronal-acetate buffer for $30 \mathrm{~min}$ to remove any excessive fixative.

After dehydration in ethanol, the cells were embedded in Araldite (Epoxy resin of Ciba Ltd., Basle). Sections were cut on an A. F. Huxley Cambridge ultramicrotome with

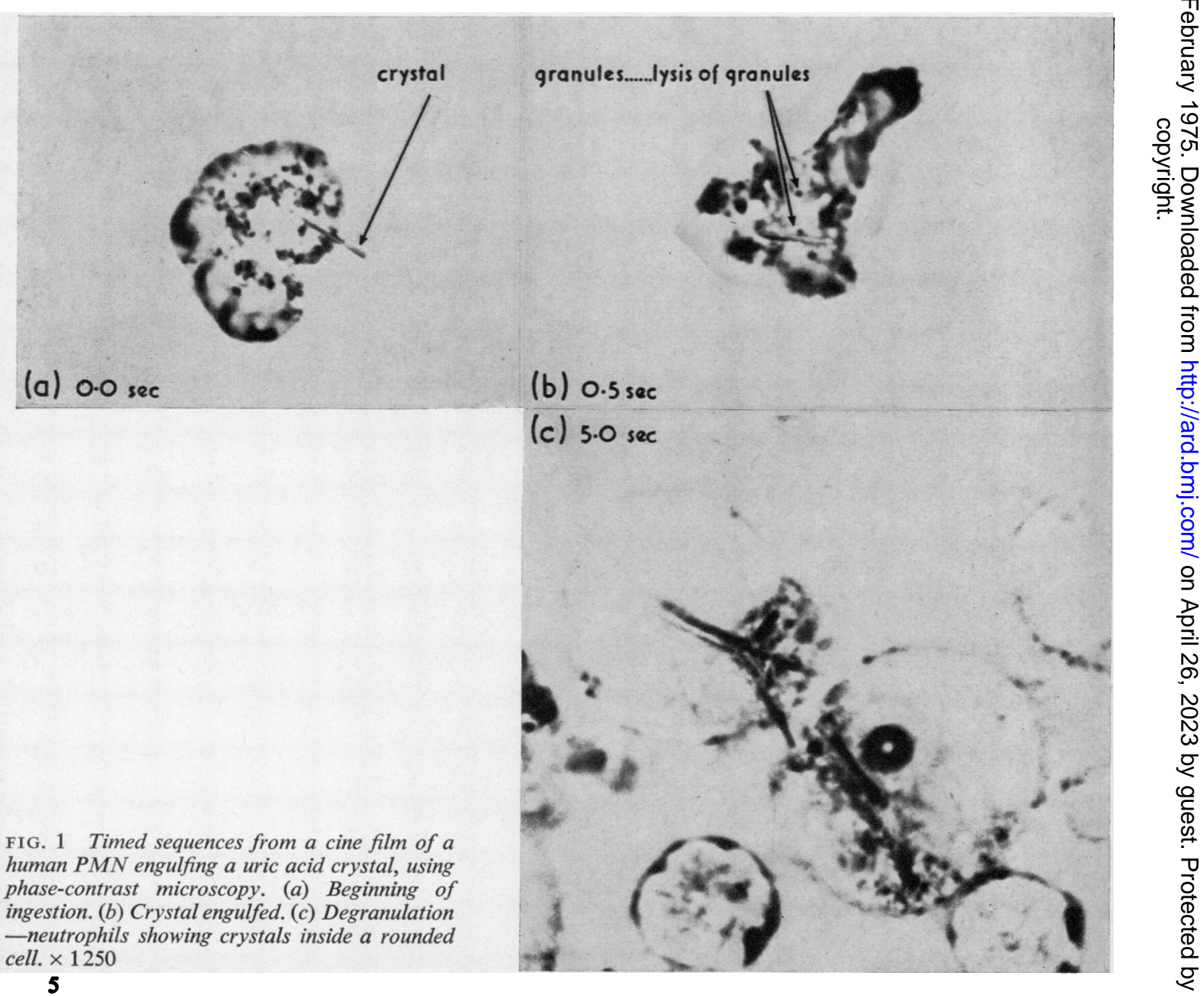


glass knives. Thick sections $(0 \cdot 1 \mu \mathrm{m})$ were examined by phase-contrast microscopy and suitable areas showing abundant cells were then sectioned at $0.05 \mu \mathrm{m}$ for electron microscopy. Thin sections were stained with uranyl acetate followed by lead citrate and examined in an AEI EM6B electron microscope operating at $60 \mathrm{kV}$.

\section{Results}

\section{PHASE-CONTRAST MICROSCOPY}

Under phase-contrast microscopy living PMNs in culture appeared rounded with numerous bright cytoplasmic granules, the polymorphic nuclei of the cells were clearly seen. Most of the leucocytes showed amoeboid movements and small processes could be seen protruding in the direction in which the cell was moving. The contents of the cytoplasm with its numerous granules were in continuous slow motion, the region taking part in the process of locomotion being devoid of granules. When the cells came in contact with adjacent cells, movement ceased, indicating contact inhibition of locomotion. When more than $1 \times 10^{6}$ cells $/ \mathrm{ml}$ were present in the initial suspension the PMNs showed very little locomotion.

When the PMNs came in contact with small crystals of uric acid (under $8 \mu \mathrm{m}$ in length), the cells became active and within a few seconds began putting out pseudopodia in the direction of the crystals; cells not taking part in this process of phagocytosis remained extremely motile. The most remarkable feature of the cellular response was the rapid movement of the granules which was observed. Pseudopodia protruded on either side of the crystal, which was then 'swallowed' by the cytoplasm; the whole process was very rapid and in the earlier experiments it was impossible to photograph the mechanism of ingestion.

Fig. 1 shows a time sequence from a cine film of a के human neutrophil leucocyte engulfing a uric acid $\overrightarrow{0}$ crystal, illustrating the speed with which the process of $\vec{\overrightarrow{ }}$ ingestion proceeded when a crystal came in contact with a PMN. After ingestion, the crystal lay inside a vacuole; the highly activated cell, judged by rapid movements of the granules, seemed to be "writhing $\omega$ in agony' with the crystal inside it. Once the cell had $\overrightarrow{.}$

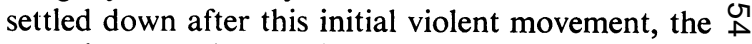
granules moved towards the surface of the vacuole $\mathrm{O}$ and seemed to vanish as they came in contact with the membrane limiting the phagosome. It sometimes T appeared as if the granule 'exploded' on coming in 을 contact with the membrane. The granules disappeared rapidly and the cell then appeared empty and rounded up. This was followed by a gradual swelling of the $\vec{\theta}$

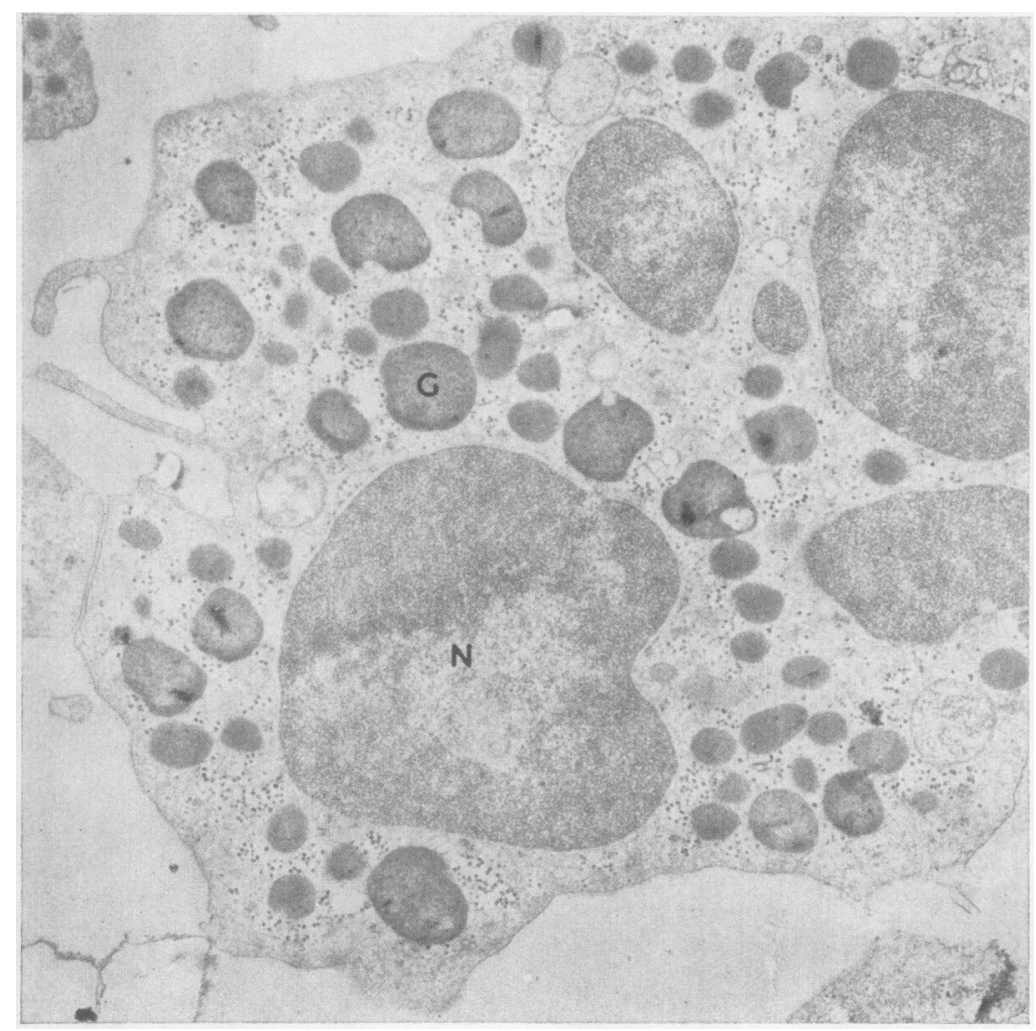

FIG. 2 Mature PMN from normal rabbit peritoneal exudate fixed for $1 \mathrm{~h}$ in glutaraldehyde, postfixed in osmium tetroxide, stained with uranyl acetate and lead citrate (Figs 29). Cellular detail with good preservation of cell architecture is shown. $G=$ granule; $N=\widetilde{N}$ nucleus. $\times 15600$ 


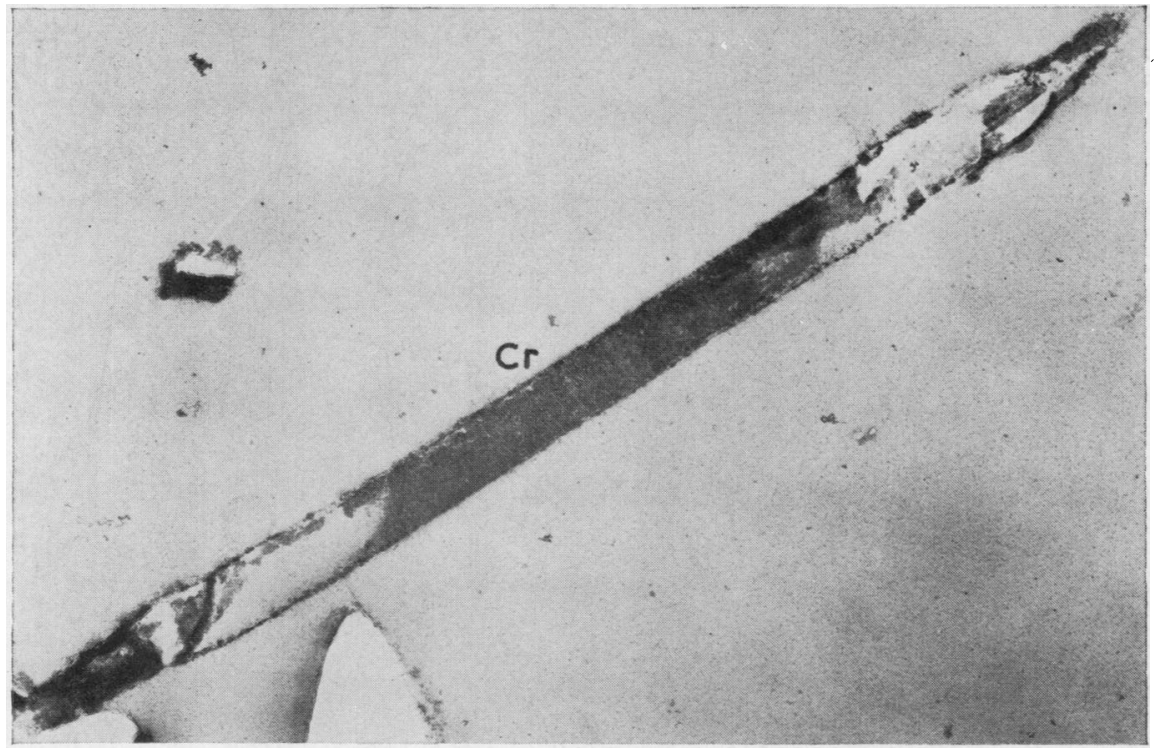

FIG. 3 Uric crystal. $\times 33100$

acid

cell which became distended and eventually ruptured, releasing the ingested crystals and cellular debris into the medium. When fresh leucocytes were added to the preparation at this stage, some ingested the debris of the dead cells. The process of phagocytosis, migration of granules to the surface of the phagocytic vacuole, followed by degranulation, cell death, and rupture, was then repeated. In some degranulated cells more than 10 crystals could be counted at one time, suggesting that the process of ingestion must proceed continuously and very rapidly indeed.

\section{ELECTRON MICROSCOPY}

Electron micrographs of thin sections of PMNs fixed with glutaraldehyde and osmium tetroxide show numerous nuclear structures (Fig. 2 N) which represent parts of a single, multilobed nucleus. The chromatin stains more strongly than the nucleoplasm and is mostly at the periphery of the nucleus. The granules (Fig. $2 \mathrm{G}$ ) in the cytoplasm are of different shapes and sizes, some being oval shaped and others rounded, depending on the plane of section; they are bounded by a membrane and have a homogeneous

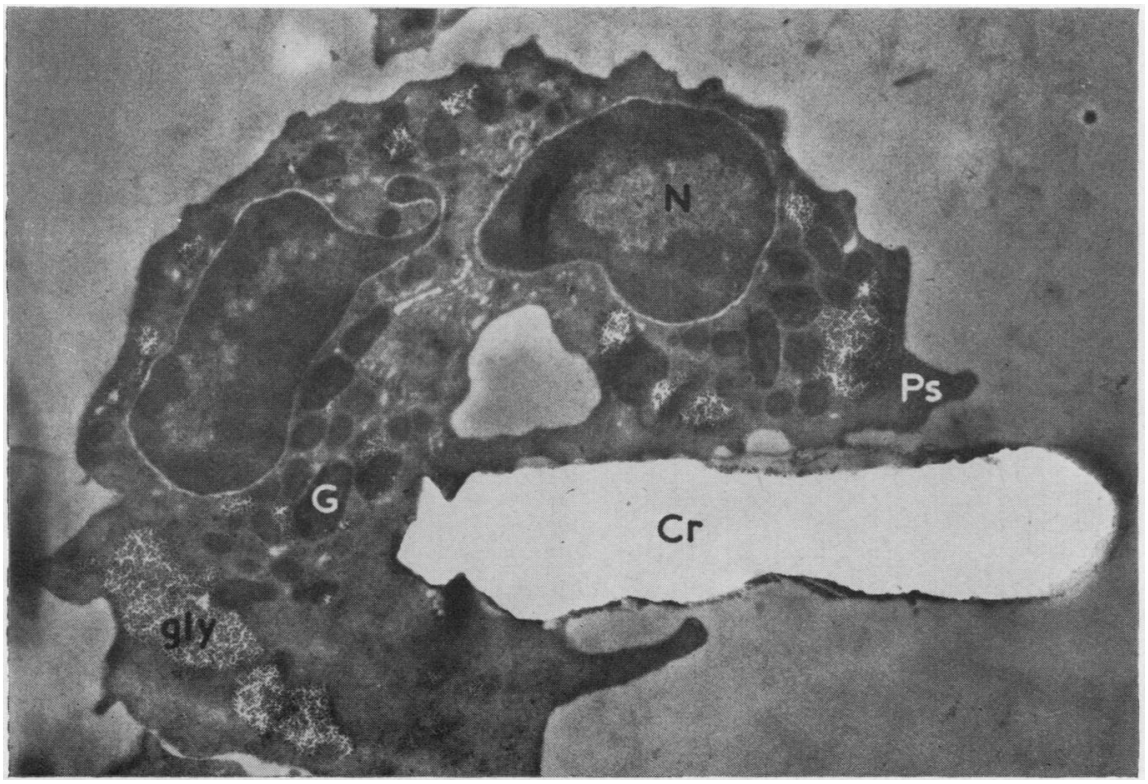

FIG. 4 PMN ingesting a uric acid crystal $(\mathrm{Cr})$. The pseudopodia (Ps) appear to be holding the crystal. Note that the cytoplasm is devoid of granules. $N=$ nucleus; $\boldsymbol{G}=$ granule; $\boldsymbol{g l y}=\mathbf{g l y}$ cogen. $\times 11700$ 


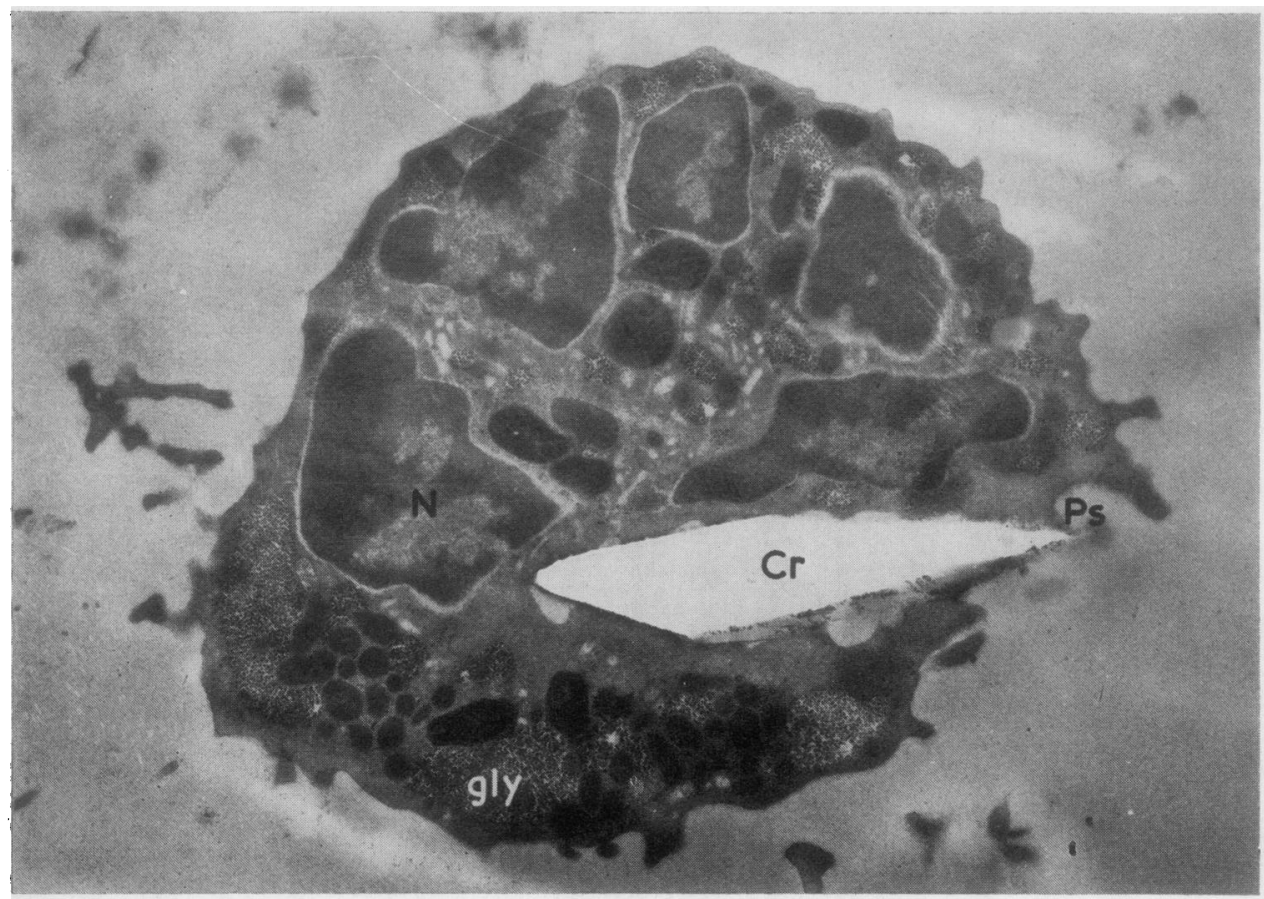

FIG. 5 PMN ingesting a uric acid crystal $(C r) . N=$ nucleus; $P s=$ pseudopodia; $g l y=$ glycogen.$\times 11200$

matrix which is dense in most cells. Apart from the granules, the other cytoplasmic structures are the Golgi apparatus, a few mitochondria, abundant glycogen, and an occasional cisternum of the endoplasmic reticulum.

The general structure of neutrophil leucocytes incubated with crystals of uric acid was well preserved in spite of the gross changes in the organization of the cytoplasm. The crystals were usually extracted from the sections while the sections were floating on the trough of the glass knife and consequently they appeared as empty areas in the electron micrographs (Fig. 4). During the process of ingestion, pseudopodia were extended towards the crystal (Fig. 4) and

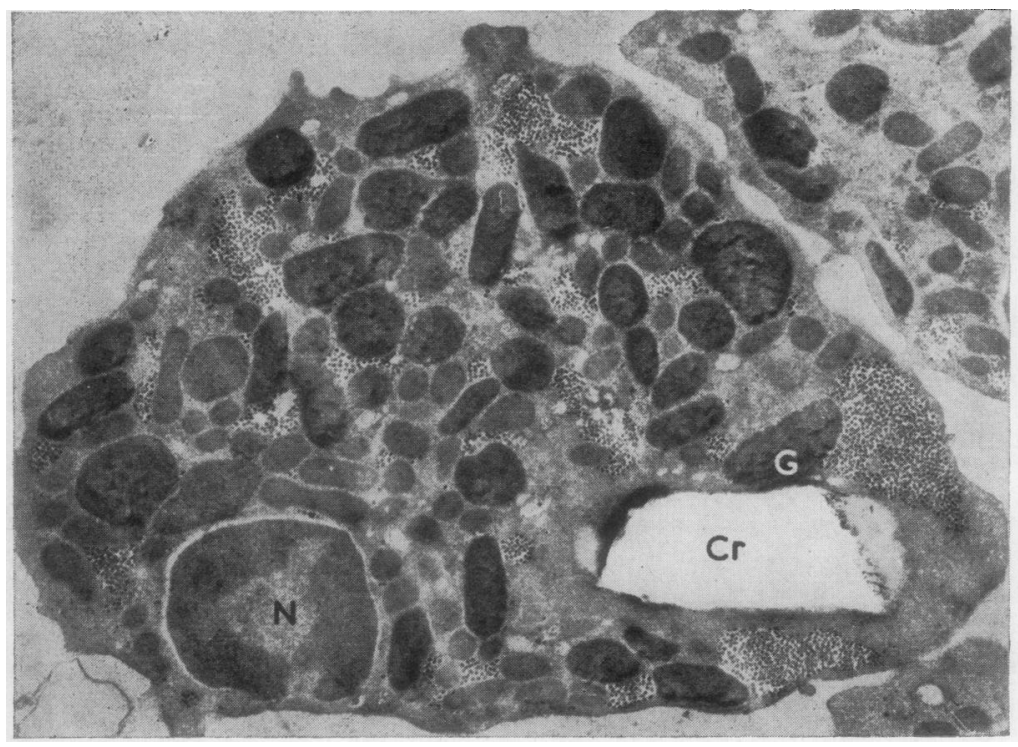

FIG. 6 PMN showing a granule (G) close to the surface of the phagocytic vacuole. $\times 14000$ 


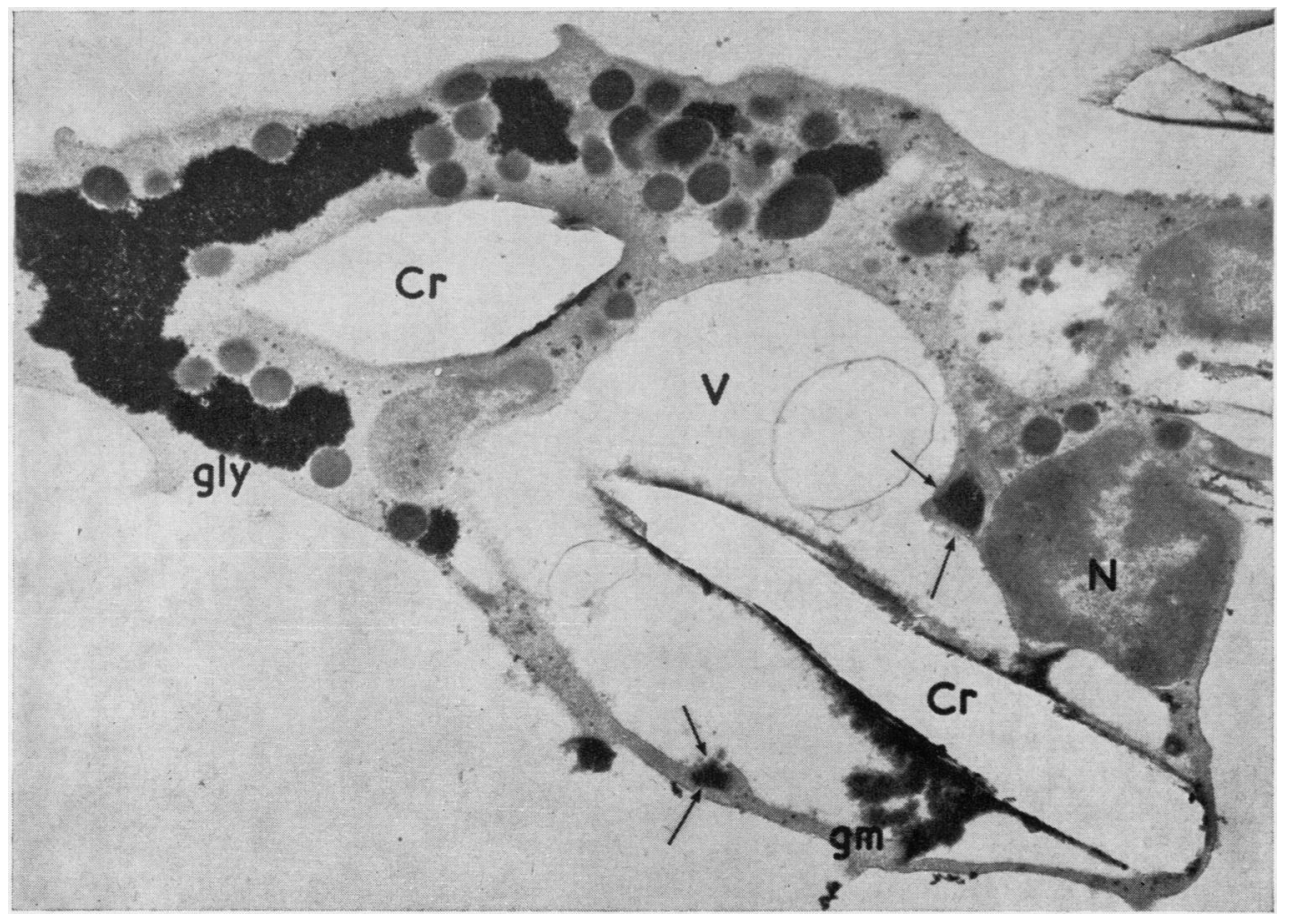

FIG. 7 PMN showing detailed features 15 min after engulfing a uric acid crystal $(\mathrm{Cr})$. At the points indicated by the arrows the membranes surrounding the granules are continuous with the membrane of the phagosome and the granule contents discharging into the vacuole $(V) . g l y=$ glycogen; $g m=$ granular material. $\times 11500$

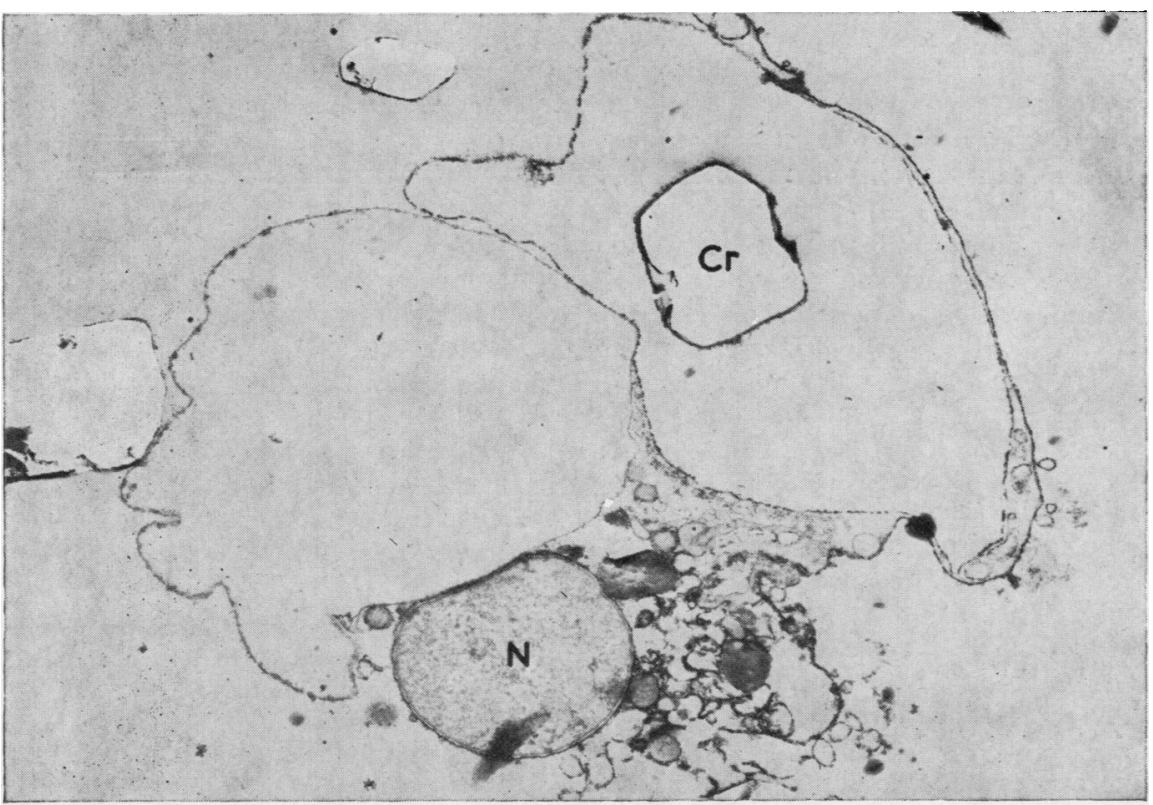

FIG. 8 Degranulated cell-'ghost cell'. $x$ 9400 


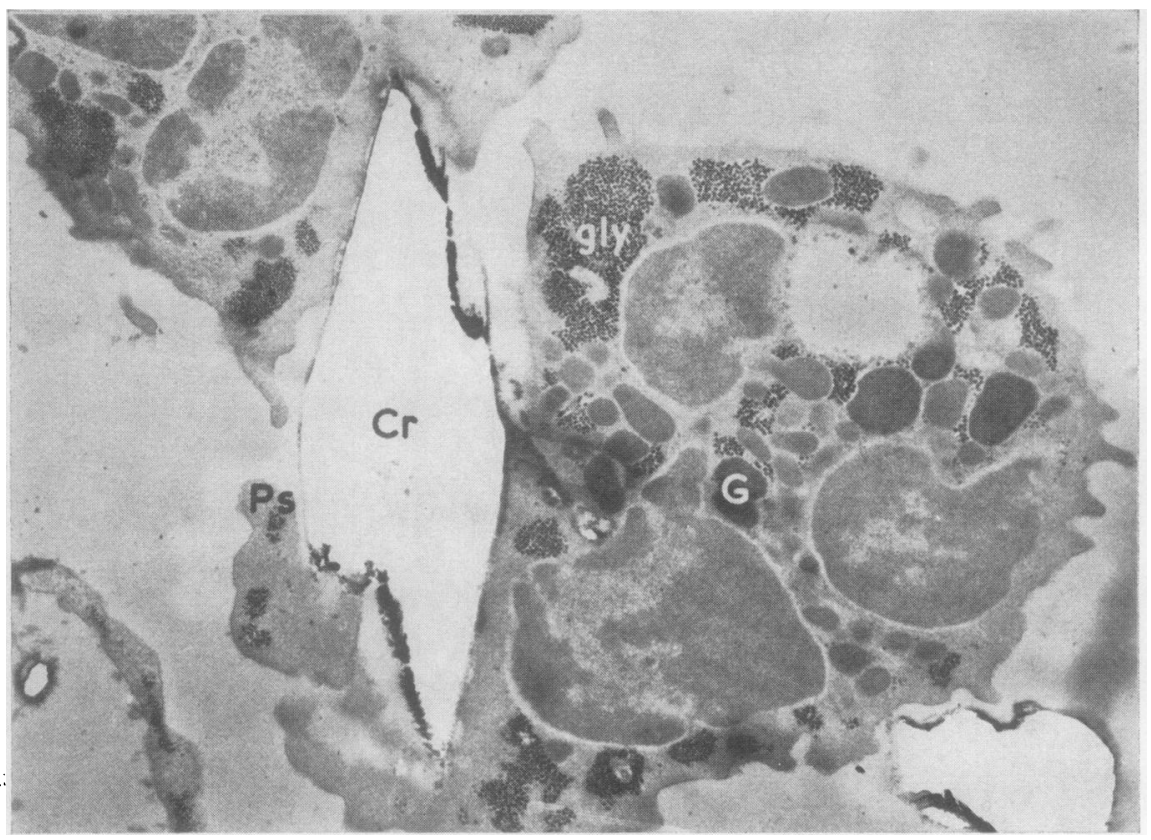

FIG. 9 Two PMNs competing for $a$ crystal. This 'tug-ofwar' was observed 10 min after incubation. $\times 11700$

became wrapped round the particle so that it appeared to be held by pincers (Fig. 5). Gradually the opposite ends of the pincers came into contact and fused with each other enveloping the crystal. Once the crystal had been ingested the neutrophil granules migrated to the surface of the phagosome (Fig. 6) and appeared to fuse with it (Fig. 7). An interesting feature was the lack of cytoplasmic granules at the site of phagocytosis (Figs 4 and 5); not until the crystals were safely within the cell did the granules show any sign of taking part in the 'attempted digestion' of the particle.

Cells fixed after $5 \mathrm{~min}$ of incubation with uric acid crystals showed more advanced stages of degranulation with much cellular debris in the environment. Some PMNs (Fig. 8) had ruptured releasing their numerous granules with nuclear debris and crystals; these can be termed 'ghost cells'-a shadow of their former selves. In one section two cells were seen competing for a crystal-in a 'tug-of-war' (Fig. 9).

\section{Discussion}

Largely through the work of Hirsch and Church (1960), Hirsch (1962), Cohn and Hirsch (1960a, b), Cohn, Hirsch, and Weiner (1963), Karnovsky (1962), Bainton and Farquhar (1966), Brewer (1963), and Brewer and Heath $(1963,1964)$, an increasing body of knowledge has accumulated on the mechanism of phagocytosis by PMNs and the ultimate fate of their granules.

In the present study, experiments made with human and rabbit polymorphonuclear leucocytes and uric acid crystals have shown that the processes of ingestion of the crystals and degranulation of the leucocytes are similar to those reported by Zucker-Franklin and Hirsch (1964) using zymogen particles, and also confirm the observations with phase-contrast microscopy reported earlier (Rajan, 1966).

In gout, crystal formation seems to be the starting point in the process of inflammation. Once crystals of the appropriate size $(0.5-8 \mu \mathrm{m})$ have been formed, this might be followed by local injury to the endothelium causing leucocytic adherence and migration, which in turn could lead to phagocytosis.

Since it is clear that PMNs ingesting crystals in vitro release enzymes which satisfy the criteria for lysosomal acid proteases, the next question to be considered is whether this in vitro reaction simulates the in vivo state in acute attacks of gouty arthritis. That it does so is indicated by the observation on synovial exudates from patients with acute synovitis, which contain nearly three times as much acid protease activity as exudates from noninflamed joints. It is logical to deduce that colchicine, a drug considered specific in abating acute attacks of gout, may partly stabilize the lysosomal granules (Rajan, 1966) or inhibit the process of phagocytosis.

I am indebted to Dr. A. G. S. Hill (Aylesbury), Dame Honor B. Fell (Cambridge), Miss A. M. Glauert (Cambridge), and Mr. R. Parker (Cambridge) for their suggestions and help during the course of this study. The work was aided by the Arthritis and Rheumatism Council for Research in Great Britain and the Commonwealth. 


\section{References}

BaInton, D. F., AND FARQuHAR, M. G. (1966) J. Cell Biol., 28, 277 (Origin of granules in polymorphonuclear leucocytes. Two types derived from opposite faces of the Golgi complex in developing granulocytes)

BREWer, D. B. (1963) J. Path. Bact., 86, 299 (Electron microscopy of phagocytosis of staphylococci) , AND HEATH, D. (1963) Nature, 198, 1015 (Lysosomes and vacuolation of the liver cell)

- - _ (1964) J. Path. Bact., 87, 405 (Development of sucrose vacuoles from liver-cell lysosomes)

Cohn, Z. A., AND HiRSCH, J. G. (1960a) J. exp. Med., 112, 983 (The isolation and properties of the specific cytoplasmic granules of rabbit polymorphonuclear leucocytes)

,$- \ldots$, (1960b) Ibid., 112, 1015 (The influence of phagocytosis on the intracellular distribution of granuleassociated components of polymorphonuclear leucocytes)

,-- , AND WEINER, E. (1963) 'The cytoplasmic granules of phagocytic cells and the degradation of bacteria', In 'Lysosomes', ed. A. V. S. de Reuck and M. P. Cameron, p. 126. Churchill, London

FaIRES, J. S., AND MCCARTY, D. J. (1961) Clin. Res., 9, 329 (Acute arthritis in man and dog produced by intrasynovial injection of sodium urate crystals)

- - - (1962) Lancet, 2, 682 (Acute arthritis in man and dog after intrasynovial injection of sodium urate crystals)

Freudweiler, M. (1899) Deutsch. Archiv. Klin. Med., 63, 266 (Experimentelle Untersuchungen über das Wesen der Gichtknoten)

GarRoD, A. B. (1859) In 'The Nature and Treatment of Gout and Rheumatic Gout'. Walton and Maberly, London

GLAUERT, A. M. (1965) 'The fixation and embedding of biological specimens', in 'Technique for Electron Microscopy', ed. D. H. Kay, p. 166. Blackwell, Oxford

HIRSCH, J. G. (1962) J. exp. Med., 116, 827 (Cinemicrophotographic observations on granule lysis in polymorphonuclear leucocytes during phagocytosis)

- AND CHURCH, A. B. (1960) Ibid., 111, 309 (Studies of phagocytosis of group A streptococci by polymorphonuclear leucocytes in vitro)

KARNovsky, M. L. (1962) Physiol. Rev., 42, 143 (Metabolic basis of phagocytic activity)

MCCARTY, D. J. (1965) Arthr. and Rheum., 8, 726 (The inflammatory reaction to microcrystalline sodium urate)

RAJAN, K. T. (1966) Nature, 210, 959 (Lysosomes and gout)

_, (1968) 'Gout-role of polymorphs', in 'Medical Monograph 3, Rheumatic Diseases', pp. 264-270. Edinburgh University Press, Edinburgh

Seegmiller, J. E., Howell, R. R., AND Malawista, S. E. (1962) J. Amer. med. Ass., 180, 469 (The inflammatory reaction to sodium urate. Its possible relationship to the genesis of acute gouty arthritis)

Zucker-Franklin, D., AND Hirsch, J. G. (1964) J. exp. Med., 120, 569 (Electron microscope studies on the degranulation of rabbit peritoneal leucocytes during phagocytosis) 